\title{
Dewey en Argentina (1916-1946): Tradición, intención y situación en la producción de una lectura selectiva
}

\author{
Dewey in Argentina (1916-1946): \\ Tradition, intention, and situation in the \\ production of a selective reading
}

\author{
Dewey en Argentine (1916-1946): \\ La tradition, l'intention et la situation dans \\ la production d'une lecture sélective
}

\author{
Marcelo Caruso \\ Humboldt-Universität zu Berlin, Alemania \\ Inés Dussel \\ FLACSO/Argentina
}

\section{RESUMEN}

A partir de la década de 1910, los educadores argentinos recurrieron repetidas veces a la obra de John Dewey en el marco de una búsqueda de modelos de reforma educativa. Sin embargo, su reputación indiscutida como uno de los mayores intelectuales del campo educativo contrastó con una visión particularmente selectiva de su obra y con una recepción muy débil de la misma en términos institucionales. De hecho, partes sustantivas de sus investigaciones fueron marginalizadas en una lectura selectiva que produjo una versión de Dewey como educador despolitizado. Las múltiples vinculaciones entre "democracia," "educación" y "escolarización" sugeridas por Dewey fueron reducidas a una peculiar "didáctica," un movimiento que reflejó las trayectorias políticas e intelectuales de los adeptos al movimiento escolanovista en el país. A partir de un análisis de artículos y comentarios sobre la obra de Dewey, la presente contribución se centra en el espectro de lecturas alternativas disponibles que se dieron en un período específico y en sus condiciones particulares de emergencia. Las tradiciones liberal y católica de lectura de modelos y referencias extranjeras serán puestas en un campo de discusión junto con 
las luchas que organizaron los juegos de enfrentamiento en el campo político del período, y particularmente con el clima de polarización política del momento (primeros gobierno elegidos democráticamente, dictaduras militares, la elección de Juan Domingo Perón en 1946). Fueron estos elementos los que marcaron la recepción de Dewey en Argentina.

Descriptores: Dewey; Argentina; Escuela Nueva; internacionalización; lectura selectiva; recepción.

\section{ABSTRACT}

From the 1910s on, Argentinean educators repeatedly looked to Dewey's work in search of models of educational reform. However, his undisputed reputation as a major thinker contrasted with a very selective view of his work and a weak reception in institutional terms. This article focuses on the marginalization of substantial parts of his scholarship in Argentina. A strong selective reading there produced a de-politicized version of Dewey as an educational reformer. The multiple relationships between "democracy" and "education" or "schooling" opened up by Dewey's thought were reduced in Argentina to a peculiar form of "didactics," in a movement that reflected the intellectual and political trajectories of the supporters of the New Education Movement. Working through translations, articles and comments on Dewey's work, we will focus on understanding the range of alternative readings that were available at a particular time, and the contexts of debate in which they became possible. The liberal and Catholic traditions of reading foreign references and models will be put together with the struggles that organized political oppositions in the period considered, and with the particularly heated climate (first democratically elected government, military dictatorships, Perón's election) that marked these years and that tainted Dewey's reception in Argentina.

Key words: Dewey; Argentina; New Education Movement; internationalization; selective reading; reception.

\section{RÉSUMÉ}

À partir des années 1910, les éducateurs argentins retournèrent à plusieurs reprises aux écrits de Dewey pour y chercher des modèles de réforme de l'éducation. Cependant, sa réputation incontestée d'être un des plus grands penseurs contrastait avec une vue très sélective et un faible accueil de son œuvre en terme de l'institution. En fait, certaines parties de son savoir érudit furent marginalisées dans une lecture sélective qui produisit une version dépolitisée de Dewey en tant que réformateur de l'éducation. Les relations multiples entre "la démocratie " et "l'éducation " ou la "scolarisation " ouvertes par la pensée de Dewey furent réduites en Argentine à une étrange "didactique " dans un mouvement qui reflétait les trajectoires intellectuelles et politiques des partisans du Nouveau Mouvement en Éducation. Dans ce chapitre, en parcourant les traductions, les articles et commentaires sur les oeuvres de Dewey, nous miserons sur la compréhension de la gamme des lectures alternatives disponibles à un moment particulier et les contextes dans lesquels les débats devinrent possibles. La tradition libérale et catholique de la lecture des références étrangères sera reliée aux luttes qu'ont organisées les oppositions politiques durant la période en considération et au climat particulièrement passionné (le premier gouvernement élu démocratiquement, les dictatures militaires, l'élection de Peron) qui ont marqué ces années et qui ont terni l'accueil fait à Dewey en Argentine.

Mots clés : Dewey; L'Argentine; le Nouveau Mouvement en Éducation; I'internationalisation; la lecture sélective.

$\mathrm{E}$ N ARGENTINA, EL NOMBRE DE JOHN DEWEY fue una referencia persistente en los debates educativos de comienzos del siglo XX, cuando su obra comenzó a ser leída y conocida por un círculo cada vez más grande de educadores. Como en el caso de otros países, Dewey fue considerado como un representante del liberalismo educativo y como un defensor del principio de actividad, de la pedagogía puerocéntrica 
y de la democracia educativa. ${ }^{1}$ Asociado con este espectro de ideas, y especialmente identificado con una particular cultura, la norteamericana, que fue su condición de emergencia, la figura de John Dewey fue tan apreciada como denostada.

Una de las situaciones más llamativas e inesperaas donde su nombre fue evocado para la polarizacíón de propuestas educativas fue una concentración política en un clima enrarecido pre-electoral unos días antes de las eleccciones generales de febrero de 1946 que dieron la victoria a Juan Domingo Perón. Durante este acto, que tuvo lugar en el conocido estadio Luna Park de la ciudad de Buenos Aires, el director del Instituto Nacional de Formación del Profesora, Jordan Bruno Genta, un conocido ideólogo fascista, proclamo frente a "25000 maestros que habían acudido al evento bajo amenaza de despido:" "La influencia perniciosa de John Dewey... debe ser erradicada de las escuelas argentinas... La escuela nueva debe ser reesmplazada por la escuela tradicional." ${ }^{2}$ Este tipo de incidentes, que tuvieron lugar en un contexto represivo marcado por una dictadura militar de clara ideología nacional-católica, solidificó la mala reputación del naciente peronismo en aquellos años. En todo caso, el mismo John Dewey comentó lacónicamente esta anécdota en una carta de lectores del semanario "Time" que había publicado el reportaje con las declaraciones de Genta: "El artículo sobre Argentina fue algo nuevo para mí. Bajo las circunstacias de ese país, lo tomo como un cumplido."3

Es realmente revelador que el nombre Dewey haya jugado un papel tan central en el retrato que Genta pintaba de los enemigos de la tradición y del nacionalismo. En estos meses dramáticos que siguieron el fin de la Segunda Guerra Mundial, el debate político se había polarizado al extremo. Uno de los polos era el de los partidos tradicionales que enfrentaban la candidatura de Perón y que iban desde los partidos más conservadores y tradicionales dominados por los grandes propietarios terratenientes de las provincias del norte pasando por los liberales progresistas de la Unión Cívica Radical y culminando por los socialistas y comunistas - una coalición denominada "Unión Democrática." Estas fuerzas plantearon la confrontación política del momento como una simple oposición entre "democracia" y "fascismo." El otro polo, el Partido Laborista que apoyaba la candidatura de Perón, construyó un claro antagonismo discursivo entre Perón y Braden (el embajador norteamericano que intervenía muy activamente en la política interior del país), una metáfora que evocaba la oposición entre el nacionalismo y el imperialismo norteamericano. ${ }^{4}$ En este contexto, en el cual posiciones pro-norteamericanas y anti-norteamericanas estructuraban el antagonismo político del momento, la mención a John Dewey no era una mera referencia académica, sino que era utilizada para producir una serie de sentidos asociadios. Éstos, casi es innecesario decirlo, eran particularmente negativos. ${ }^{5}$

La mención del nombre de Dewey por Jordán Bruno Genta en medio de una de las elecciones más importantes de la historia política argentina del siglo XX ilustra el poder del nombre de Dewey para movilizar patrones locales de sentido y de acción. Debe notarse aquí que el ascendente de Dewey en la educación argentina no era significativo en ese tiempo y la pregunta misma acerca de si los miles de maestros asistentes a esta concentración política entendieron la referencia mencionada no puede ser contestada con seguridad. De todas maneras, la referencia a la obra de Dewey 
implicaba para muchos contemporáneos conceptos y posiciones relacionados a prácticas de recepción de saberes y modelos "extranjeros" así como también a prácticas de autoafirmación. La Obra de Dewey no podía ser ignorada durante el período de entreguerras pero, al mismo tiempo, su conocimiento no implicaba necesariamente una recepción general favorable de sus posiciones y tesis centrales.

En el presente artículo, queremos presentar evidencias que apuntalan el argumento de que el destino de las ideas de Dewey en el campo educativo argentino de los años de entreguerra muestra una proceso particularmente selectivo de lectura que no desembocó en la formación de una relectura y apropiación significativa de sus textos. Al considerar las traducciones, artículos y comentarios sobre la figura de Dewey, no estamos buscando las "desviaciones" de una versión "verdadera" de Dewey, sino que intentamos mostrar el espectro de las lecturas alternativas que estuvieron disponibles en un período determinado y los contextos de debate que las hicieron posibles. De las numerosas estrategias posibles de análisis, nos concentraremos en los problemas a los que se enfrentaban los educadores argentinos cuando hablaban de democracia en la educación y en las escuelas y en el papel que la referencia a Dewey como autor reconocido jugó en la formulación de estos problemas.

\section{Los primeros lectores de Dewey: Traducciones y dislocaciones del liberalismo}

Como hemos dicho, la obra de Dewey fue ampliamente leida en numerosos países, y esta lectura combinaba el avance de un movimiento pedagógico internacional co nla construcción de verdaderas "escenas" educativas nacionales en aquellos años. Esta combinación de pedagogías que circulaban internacionalmente y los campos de producción e interpretación nacionales parece haber sido particularmente importante en Argentina donde, desde su independencia del imperio español, la búsqueda de legitimación y solidez en el proceso de modernización había sido procesada frecuentemente con la ayuda de modelos y "autoridades" extranjeros. ${ }^{6}$ Las elites argentinas imitaron con entusiasmo el modelo francés de escolarización centrado en una escuela primaria común, obligatoria, gratuita y de laicidad restringida e importaron concientemente el positivismo francés, el cual se convirtió en la filosofía educativa fundante del sistema moderno escolar del país. En la primera década del siglo XX, las fuerzas educativas que sostenían el programa positivista se impusieron definitivamente e impusieron su particular diseño del sistema escolar, el cual contenía un programa pedagógico marcado por el cientificismo y por la propagación de vínculos pedagógicos racionalizadas y más bien autoritarios. ${ }^{7}$ Este programa asoció la expansión de la escolarización con la construcción del Estado-nación.

Fue en este contexto en el cual el desafío representado por la obra de Dewey fue registrado y discutido por primera vez. En general, la educación norteamericana constituía una referencia más bien marginal para los reformadores educativos argentinos, los cuales usualmente eran atraídos por las reformas llevadas a cabo en Europa. En el campo cultural, durante las primeras décadas del siglo XX, las referencias para la legitimación de la experiencia "nacional" eran buscadas tanto en la herencia hispánica o en 
figuras "nativas" como el gaucho o los indios. ${ }^{8}$ Pero en el campo educativo, la preferencia por el modelo norteamericano era algo arcaica y se encontraba indisolublemente asociada a la personalidad por demás destacada de Domingo Faustino Sarmiento (1811-1888), educador de fuste y presidente del país en el siglo XIX. Sarmiento había viajado a los Estados Unidos en 1845 y 1846 por encargo del gobierno chileno, donde él estaba exiliado, y fue más tarde embajador de Argentina en aquél país. Renunció a este cargo para retornar a Buenos Aires como presidente electo en 1868. Era amigo de Horace y Mary Mann y estaba particularmente impresionado por la experiencia de desarrollo de un sistema escolar estructurado de fuerte base social, tal como se estaba dando en los estados federados norteamericanos en aquellos años. Cuando fue designado Director de Escuelas de la Provincia de Buenos Aires, ensayó reformas significativas a nivel local en las cuales dio impulso a los concejos escolares de distrito, copiados del modelo escolar de las escuelas comunes, como elemento central de estructuración del sistema escolar. Como presidente, promovió la inmigración de 65 graduadas de las escuelas normales norteamericanas, las cuales tuvieron una influencia significativa en la creación de las diversas escuelas normales en Argentina. ${ }^{9}$

Pero la posición pro-norteamericana de Sarmiento sería un ejemplo solitario por varias décadas. Junto con una serie de causas políticas y económicas (entre ellas, la competencia entre Argentina y Estados Unidos por un rol líder en América Latina), ${ }^{10}$ el clima intelectual de la Argentina de fin de siglo experimentó la popularidad de un movimiento claramente antinorteamreicano conocido como "arielismo." Influenciado por la derrota española en la Guerra de Cuba en 1898, el uruguayo José E. Rodó se dirigió a la juventud latinoamericana denunciando los peligros de la expansión imperialista norteamericana en América Latina, la cual ya se percibía en la tentación "materialista" que estaría atravesando a la cultura latinoamericana y que Rodó personificó en el espíritu de Calibán trayendo modas y valores norteamericanos. ${ }^{11}$ Este movimiento favoreció claramente repsuestas antiliberales y debilitó el apoyo a alternativas educativas basadas en modelos vinculados a la experiencia norteamericana.

Algunos investigadores han afirmado que Argentina, después de España, habría sido el país más receptivo a las ideas de Dewey en las primeras décadas del siglo XX. ${ }^{12}$ Sin embargo, esta afirmación carece de fuerte evidencia empírica para su fundamentación. La primera traducción de Dewey al castellano, "Mi credo pedagógico" (original de 1897), fue publicada por el educador chileno Darío Salas en Santiago de Chile en 1908. Las primeras traducciones al castellano de libros de Dewey, "La escuela y la sociedad" (original de 1899) y "Psicología del pensamiento" (original de 1910), fueron publicadas respectivamente en Madrid (1915) y en Boston (1917). Los educadores españoles fueron particularmente activos en la traducción y publicación de la obra de Dewey hasta el desenlace de la Guerra Civil Española.

Solamente en el caso de "Psicología del pensamiento" puede apreciarse un interés argentino en la traducción y difusión de las ideas deweyanas. Ernesto Nelson (1873-1959), un inspector de escuelas que había concurrido a cursos de la Universidad de Columbia en Nueva York entre 1902 y 1906, escribió un prólogo para este libro que había sido traducido por el estudiante argentino Alejandro Jascalevich. Nelson y Jascalevich se habían conocido en la escuela secundaria experimental que dependía de la Universidad 
de La Plata, la primera universidad de investigación del país. Nelson era el director del Consejo escolar de esta institución reformista mientras que Jascalevich fue uno de sus primeros graduados. ${ }^{13}$ A pesar del hecho de que los textos publicado por Dewey durante las primeras tres décadas del siglo XX estaban vinculados a la educación, Nelson mostró en su prólogo un conocimiento profundo de su trabajo filosófico. En su introducción a esta "psicología," Ernesto Nelson apuntó al hecho de que en la filosofía de Dewey "democracia" significaba siempre "evolución;" "el establecimiento de la psicología como una ciencia natural" y "el método científico" constituían las marcas fundamentales de la civilización moderna. ${ }^{14} \mathrm{El}$ nuevo "estado de la vida colectiva” habría descartado posiciones dogmáticas y sus fundamentos filosóficos tales como el concepto "realista" de verdad. Nelson argumentaba que "democracia" estaba asociada a la pérdida de las fuentes absolutas de autoridad y, consecuentemente, incitaba a los individuos a ser activos participantes de la vida social ya que todas las jerarquías entre "ratio" y experiencia habían perdido su relevancia. ${ }^{15}$ Él reconocía el hecho de que el sistema filosófico de Dewey, aunque fuera una fuente de inspiración fundamental para reformas educativas, era más que una filosofía educativa y citaba al propio Dewey que había expresado que la filosofía no era otra cosa que una "teoría educativa generalizada." Para Nelson, el tiempo en el cual "educación y democracia” tenían que convertirse en términos correlativos había llegado definitivamente a América Latina. ${ }^{16}$

Nelson convocó a una renovación general de las discusiones educativas las cuales debían basarse crecientemente en las "lecciones de los hechos." La tarea "urgente" para todo el continente era la "liberación del dogmatismo, de la convención y verdades a medias." ${ }^{17}$ Nelson era un norteamericanista convencido: fue unos de loas fundadores del Instituto de Cultural Argentino Norteamericano (ICANA) y del Rotary Club, escribió numerosos libros y artículos sobre la cultura y las instituciones de aquél país. ${ }^{18}$ Por todo ello, fue acusado "cariñosamente" por uno de los pedagogos del establishment positivista de cultivar un "yanquismo enardecido." 19

Por supuesto, Nelson no fue el único educador argentino que tuvo un conocimiento extenso de la obra de Dewey. Raúl Díaz (1862-1918), uno de los inspectores en jefe del Ministerio de Educación de la Nación, también compartía muchas de las ideas de Dewey como parte de una política cultural democrática. Díaz había sido comisionado por el gobierno argentino a visitar los Estados Unidos en 1907-1908. ${ }^{20}$ Volvió profundamente impresionado por lo que había visto y trajo consigo una multitud de documentos sobre experiencias de gobierno escolar con participación de los niños. Enfatizó el compromiso de Dewey con la democracia y su consideración de la educación tanto desde el aspecto social como desde el psicológico.

Estos elementos de filosofía pragmatista y la introducción del tema de la "democracia” tanto en el currículum escolar como en la vida escolar distinguían a Nelson y a Díaz de otros autores más preocupados por el problema de la reforma de la enseñanza y de una nueva didáctica. Nelson, en particular, formuló su énfasis centrado en la "democracia” en un momento muy especial de la vida del país. La política democrática alcanzó su primer momento de fuerte gravitación con la nueva ley electoral de 1912 y la consecuente victoria de la Unión Cívica Radical, un movimiento de las clases medias reformistas, en las elecciones de $1916 .{ }^{21}$ En ese momento, parecía posible y 
apropiado reorientar el sistema educativo bajo el nuevo gobierno "radical" que permaneció en el poder hasta 1930. Pero, al mismo tiempo, estos gobiernos reformistas tenían que lidiar con una trayectoria heredada bastante exitosa de desarrollo escolar.

En el sistema educativo, los radicales dieron impulso a algunas reformas en las universidades - donde un movimiento estudiantil de base produjo considerables cambios a partir de 1918 - y en la formación para el trabajo, pero no tocó la estructura educativa heredada. ${ }^{22}$ De esta manera, las políticas educativas favorecieron claramente la expansion de las estructuras existentes y casi no afectaron la cultura institucional de las escuelas argentinas. Aunque la promesa de democracia política era central en la agenda social, la ola "democrática" no llegó al campo educativo en toda su fuerza.

Sin embargo, las políticas educativas permitieron la existencia de numerosas iniciativas a nivel pedagógico-didáctico y esto determinó los intereses de los nuevos lectores de la obra de Dewey. En la atmósfera política y cultural particularmente liberal de la década de 1920, los educadores liberales y radicales que había enfrentado al status quo educativo (y político) comenzaron a traducir y leer textos de Dewey. Aunque su figura era bien conocida entre los docentes, las lecturas de los maestros de la obra de Dewey que enfatizaban la cuestión de la democracia no sobrepasó los límites restringidos de ciertos círculos vanguardistas.

En los años siguientes, los educadores argentinos de diversas tendencias como el catolicismo, el marxismo o los espiritualistas liberales miraros a las ideas de Dewey con cierto desprecio y afirmaron que las mismas, por diversos motivos, no eran convenientes ni realizables para el desarrollo ulterior de las escuelas argentinas. Aunque Dewey fue respetado como educador - y fue casi desconocido como filósofo - se convirtió en un "clásico" moderno del pensamiento educativo, lo que condujo, irónicamente, a la marginalización de su obra y posiciones en las discusiones educativas de la época. ${ }^{23}$

\section{El primer paso hacia la marginalización: Visiones opuestas y rechazo general de Dewey en la década de 1930}

Este cambio ocurrió claramente durante la década de 1930, cuando el movimiento escolanovista se convirtió paulatanimante en la pedagogía oficial de los gobiernos fraudulentos y conservadores e, incluso, del corto gobierno militar surgido del golpe de estado de 1930, todos con una orientación cultural ligada al catolicismo conservador. Juan Bautista Terán (1880-1938), presidente del Consejo Nacional de Educación entre 1930 y 1932 bajo el gobierno militar de José E. Uriburu, lideró un movimiento de "espiritualización de la escuela" de fuertes reminiscencias nacional-católicas. ${ }^{24}$ Terán criticaba a ambas corrientes existentes, el positivismo y el pragmatismo, a las cuales acusaba de reducir al niño a un "haz de instintos y tendencias." En su opinión, "la escuela no debía ser un simple gimnasio para despertar y dar plenitud a las espontaneidad infantil," como lo pretendían Dewey y Montessori. ${ }^{25}$ El objetivo de la educación, en la vision de Terán, debía ser la formación de un ser moral con libertad y responsabilidad.

Terán consideró a Dewey como un filósofo naturalista, un simple heredero de Rousseau. "El practicismo de Dewey deja de lado el fin puramente intelectual y el fin 
ético, o los considera implicados en la enseñanza adaptada a las conveniencias e imposiciones del medio en que ha de desenvolverse el niño. Es una aplicación estricta del pragmatismo, de la doctrina característica de su raza y de su país, según la cual la utilidad es el fin supremo de la filosofía." 26 Terán no sólo afirmaba que este sistema filosófico era éticamente peligroso sino que lo condenaba como un fracaso histórico en el marco de la crisis de la economía mundial que había comenzado con la crisis estadounidense de 1929. En su mirada, la incapacidad de lograr bienestar mataerial y su desdén de la cultura contemplativa y especulativa, la cultura "pura," habría llevado a ese país a la bancarrota. Obviamente, pensaba que no era convenientente seguir ese modelo sino, por el contrario, era necesario combatirlo.

Terán defendió el espiritualismo como una filosofía educativa que implicaba el retorno a la inteligencia y que era opuesta al "culto a la vida" que sería típico del pragmatismo. ${ }^{27}$ Era un defensor del currículum humanista tradicional y negaba el valor educativo de la formación profesional porque esto significaba "condenar al pueblo a vivir en el empirismo y cerrarle el acceso a las más altas posibilidades de la inteligencia." ${ }^{28}$ En su argumentación, el activismo tenía que estar subordinado a la disciplina, al orden y al respeto a las reglas, todos principios pedagógicos del gobierno militar. La escuela nueva que Terán y sus colaboradores tenían en mente era similar a aquella que se desarrolló en la Italia fascista. La posición de Terán determinó durante la década de 1930 un clima donde las experiencias más radicalizadas al interior del escolanovismo argentino fueron perseguidas y muchos de sus adherentes fueron exonerados.

Este tipo de lectura de la obra de Dewey, aunque parezca tan limitado y tendencioso, no estaba confinada al catolicismo conservador de las derechas políticas. Puede sorprender el hecho de que se encuentren numerosas reminiscencias entre la visión de Dewey promovida por Terán y la de Aníbal Ponce, un profesor expulsado del Instituto del Profesorado por su afiliación al Partido Comunista. Ponce (1898-1938) condenó la pedagogía de Dewey como un expresión meramente utilitaria y puramente metodológica de la civilización burguesa norteamericana. Inscribió su posición crítica en un marxismo de fuerte carácter determinista. Veía la obra de Dewey en el marco de una "tendencia metodológica" de la escuela nueva que buscaba aumentar la performance de los alumnos ajustando la pedagogía a la personalidad del niño, tanto en su aspecto biológico como en el psicológico. ${ }^{29} \mathrm{El}$ reclamo de Dewey por trabajos en grupo en la escuela era interpretado como una respuesta al fordismo capitalista que requería una nueva escuela basada en la socialización puerocéntrica de los alumnos en lugar del individualismo de las escuelas tradicionales. En la visión de Ponce, Dewey y Montessori representaban modelos equivalentes de racionalización capitalista de la enseñanza.

La condena de Ponce sobre la obra de Dewey y sobre la totalidad del movimiento escolanovista estaba vinculada a un reduccionismo de clase que estructuraba su discurso y que lo llevó a negar las dimensiones nacionales específicas de la discusión educativa o cualquier otro tipo de mediación o matiz. ${ }^{30}$ Esta parcialidad lo llevó a aceptar las equivalencias discursivas establecidas en el campo educativo argentino que asociaban a la pedagogía de Dewey con un movimiento eficientista basado en la educación manual y en la formación por el trabajo. ${ }^{31}$ Otro aspecto importante de su rechazo de la obra de Dewey fue la admiración que tradicionalmente los partidos políticos de izquierda en Argentina 
habían desarrollado hacia la figura de Sarmiento y su misión "civilizadora," haciendo que la izquierda formara parte de lo que podría denominarse la gramática pedagógica oficial. ${ }^{32}$ De esta manera, la izquierda criticó todas las reformas que habían intentado disputar la legitimidad del bachillerato clásico tradicional para la escuela secundaria. ${ }^{33}$

Atacado tanto por pedagogos de la izquierda como de la derecha, Dewey tuvo pocos fieles seguidores en estos años. Entre ellos, se encuentra otro hombre de izquierdas que estuvo abocado a la propagación del ideario escolanovista con gran firmeza. El maestro Jesualdo Sosa (1905-1982), un uruguayo con vasta trayectoria y experiencia en Argentina, tenía una visión bastante diferente de la escuela nueva y de la obra de Dewey que la que se presentaba en la obra de Ponce. Consideraba que Dewey era "uno de los partidarios burgueses más progresistas" en el campo del trabajo escolar y que como figura intelectual estaría preparando la escuela socialista del futuro. ${ }^{34}$ La propuesta de Dewey, continuaba Jesualdo, articulaba el trabajo escolar a la inteligencia y a la democracia, ambos aspectos descuidados por Kerschensteiner, en el cual Jesualdo veía la personificación de la tendencia escolanovista más conservadora. Jesualdo registraba también la influencia del fordismo y del taylorismo en la obra de Dewey pero caracterizaba sus conceptos como "evidentemente progresistas" 35 en comparación con los medios y objetivos educativos de sus predecesores. Uno de los comentarios negativos de Jesualdo hacia la obra de Dewey era el papel jugado por la religión, una posición que en América del Sur estaba muy asociada al conservadurismo católico. Una vez más, Jesualdo se destacaba en el campo de las izquierdas políticas cuando reconocía que el término "religión" podría incluir también algún tipo de misticismo constructivo y "necesario para la perfección humana" y, por consiguiente, no condenaba la religión in toto. ${ }^{36}$ Por ello, Jesualdo fue uno de los pocos pedagogos de la izquierda política que tendieron puentes al espiritualismo religioso imperante en algunos círculos intelectuales. ${ }^{37}$

En el campo educativo mismo, la reacción de Terán fue aquélla que tuvo mayor impacto en las lecturas preponderantes de la obra de Dewey en las décadas de $1930 \mathrm{y}$ 1940, y no la visión de Jesualdo. Sin embargo, existe cierta evidencia de que algunos maestros estudiaban la obra de Dewey en círculos autnónomos y alejados del control oficial. ${ }^{38}$ Correlativamente con estas lecturas críticas de la derecha y de la izquierda, la popularidad de Dewey entre los maestros creció cuando sus textos fueron más "pedagógicos" y menos "políticos," pudiendo ser desvinculado, de esta manera, del credo liberal-democrático, un desplazamiento que se verá en la próxima sección. Esta transformación parece ser particularmente consistente con el perfil cada vez más "técnico" y despolitizado del movimiento escolanovista argentino, cuando sus voces más radicalizadas fueron censuradas y perseguidas. ${ }^{39}$

\section{El segundo paso hacia la marginalización: Dewey en las lecturas del movimiento magisterial (1920-1946)}

Un foco adicional de difusión de la obra de Dewey que circulaba en cierta manera por fuera de los circuitos intelectuales más oficiales era el de la prensa educativa magisterial. Ya hemos afirmado el papel relativamente marginal jugado por Dewey y por el pragmatismo norteamericano y su filosofía política en las visiones de la educación y su 
reforma de los educadores argentinos. A continuación se presentarán testimonios de las estrategias desplegadas por los maestros escolanovistas frente a la obra de Dewey. Estos testimonios se han recogido de un rastreo de dos órganos de publicación centrales del campo educativo de entreguerras. ${ }^{40}$ En primer lugar, La Obra, el semanario de mayor circulación de la época escrito por maestros. En segundo lugar, El Monitor de la Educación Común, la publicación oficial mensual del Consejo Nacional de Educación en la que participaban numerosos docentes y que era distribuida gratuitamente a todas las escuelas de la jurisdicción nacional. Aunque El Monitor no fuera un periódico escrito directa o exclusivamente por los maestros, ellos comenzaron a jugar un rol más significativo en su redacción desde la década de 1920. Ambas revistas dieron forma a las discusiones educativas de la época y pueden ser tomadas como representativas de la corriente central del pensamiento educativo de los maestros argentinos.

Basándose en la cantidad de las referencias a Dewey en estas revistas, no cabe ninguna duda de que el mismo era visto como un símbolo del escolanovismo; según un autor, Dewey era "la personalidad más saliente del actual momento pedagógico nortemaricano." ${ }^{41}$ La docente neoyorquina Estelle Jovin reforzó esta impresión de Dewey como cesura en la historia educativa en su conferencia en la Facultad de Filosofía y Letras de la Universidad de Buenos Aires en 1934: "En Norte América consideramos que el verdadero principio de la educación moderna o progresiva data de 1896, cuando Juan Dewey inició su escuela experimental en la Universidad de Chicago." ${ }^{42}$ Dewey era presentado como el personaje más conspícuo de la posición mayoritaria de la pedagogía nortemericana. En una conferencia radial del mismo del año 1931 que fue publicada por El Monitor, Dewey celebraba el progreso educativo norteamericano y enfatizaba el avance de la escolarización a pesar de sus deficiencias. Afirmaba que los norteamericanos habían hecho lo mejor posible en alcanzar los valores identificados con el "gran sueño americano." Probablemente, sus comentarios críticos y pesimistas sobre la sociedad moderna tecnologizada y la escolarización no eran de interés para los editores argentinos de la publicación oficial dado que la visión más entusiasta acerca del progreso de la escolaridad moderna había sobrevivido para Dewey incluso la crisis de $1929 .{ }^{43}$ Pero también es destacable que este artículo que elogiaba a los Estados Unidos fue publicado durante el período de la administración de Juan B. Terán, cuyo anti-deweyismo fue presentado en la sección anterior. Esto muestra que la revista oficial gozaba de un cierto grado de autonomía intelectual y que sus vínculos con los discursos educativos que circulaban en el campo educativo excedían en mucho los límites de las pedagogías "oficiales."

En las décadas de 1930 y 1940, existieron numerosas referencias a Dewey, muchas de las cuales eran muy superficiales y breves, ${ }^{44}$ y que lo presentaban por lo general como parte de una influencia de mayor envergadura de la educación norteamericana en América Latina. ${ }^{45}$ Las escuelas norteamericanas - escribió el maestro Bustos de la provincia de La Rioja - eran exitosas en mostrar, junto con los desarrollos en Italia, Alemania, Bélgica y Rusia, la "realidad” de la Escuela Nueva. Pero Bustos también lamentaba que casi nadie conocía al "sabio educador Dewey" en las provincias más distantes del norte argentino. ${ }^{46}$ Es muy probable que el prestigio de Dewey estuviera vinculado a una audiencia urbana interesada en cuestiones de reforma escolar 
y cercana al ideario escolanovista.

Junto con estas referencias superficiales a la obra de Dewey, sólo unos pocos textos escritos por él mismo circulaban en estas publicaciones. En La Obra, algo más vinculada a los movimientos escolanovistas, la mayoría de las referencias se agotaban en algunos fragmentos de la obra de Dewey y en una conferencia, además de las reseñas sobre su trabajo. ${ }^{47}$ En la revista oficial, El Monitor, solo se publicó la conferencia radial ya mencionada en $1931 .{ }^{48}$ Existe una continuidad llamativa entre la consideración de la obra de Dewey en estas revistas y las publicaciones previas. Todas ellas privilegiaron exclusivamente los textos educativos y descartaron sus trabajos filosóficos y políticos. Los argentinos percibían a Dewey fundamentalmente como un educador, mientras que el trasfondo filosófico del pragmatismo jugó un papel mucho menor en el conocimiento de los modelos norteamericanos de reforma. ${ }^{49}$

El limitado alcance de las lecturas de la obra de Dewey continuó durante todo el período. Los comentarios publicados sobre "El niño y el programa escolar" en La Obra en el año 1925 son casi paradigmáticos: El autor de la reseña menciona, por un lado, que Dewey se destaca entre los autores contemporáneos "por el papel eminentemente social que da a la escuela." Pero su comentario más extenso del libro era la crítica de la artificialidad de las asignaturas como unidad básica del programa escolar, esto es, se centraba en un aspecto estrictamente pedagógico y no en las cuestiones sociales de la educación. ${ }^{50}$ Un maestro de la distante provincia de Misiones, por su parte, identificaba a John Dewey con la crítica del modelo didáctico rígido de Herbart. ${ }^{51}$ Una muy conocida líder del movimiento gremial docente de aquellos días, Rosario Vera Peñaloza, mencionaba a Dewey como un apoyo valioso en la crítica contra el pupitre escolar tradicional, el cual habría sido diseñado solamente para escuchar y mirar al maestro y que era un estorbo en la promoción de verdaderas actividades en el aula. ${ }^{52}$ En esta línea, Dewey era también mencionado en la presentación de los centros de interés decrolyanos, incluso a pesar del hecho de que Dewey había forjado un concepto de interés mucho más flexible y en tensión con la versión médica y naturalista de Décroly. ${ }^{53}$

Existen algunas excepciones a este tipo de lecturas de la obra de Dewey. Lorenzo Luzuriaga (1889-1959), un educador español de gran fama que vivió exiliado en Argentina luego de la derrota de la Segunda República española, jugó un papel crucial en la popularización de la figura de Dewey en los círculos progresistas y, al hacerlo, intentó remarcar otros aspectos del pensamiento pedagógico deweyano. Luzuriaga no sólo tradujo varios escritos de Dewey, sino que intentó reconsiderar su trabajo bajo una perspectiva diferente a la didactista de los educadores argentinos. Todavía radicado en España, Luzuriaga había comentado y traducido obras de Dewey desde mediados de la década de 1910. Una vez llegado a Argentina, publicó una gran cantidad de artículos sobre su figura. Quizas el más importante de ellos fue la publicación de su traducción de "Experiencia y educación" en Buenos Aires en 1939. La publicación de esta obra puede ser considerada como el segundo esfuerzo más significativo de diseminación de una imagen más compleja de la obra de Dewey en Argentina, luego de los esfuerzos de Nelson de 1917.

Luzuriaga analizó la obra de Dewey como una pieza fundamental de la psicología moderna y veía en la perspectiva deweyiana del funcionamiento de la mente su 
contribución más original, una especie de diferentia specifica que lo destacaba del amplio grupo de educadores escolanovistas. Las capacidades atomizadas y clasificadas, las cuales debían ser desarrolladas a través del entrenamiento, no serían el fundamento de la mente en esta visión, sino la organización de la experiencia sería el elemento crucial. Sobre esta base, continuaba, es casi obligatorio entender a la vida escolar como una vida social en miniatura ya que las experiencias son básicamente un producto de la interacción social. Luzuriaga presentaba la obra de Dewey como habiendo reasignado la pedagogía al interior del marco del progreso social y de la crítica. ${ }^{54}$ Asimismo, defendió la introducción del trabajo manual en las escuelas, lo cual él consideraba que implicaba instruir en "métodos para la vida," negando que el trabajo manual fuera un mero entrenamiento vinculado al oficio. ${ }^{55}$ También Ernesto Nelson había tratado de enfatizar los aspectos sociales del ideario educativo deweyiano. ${ }^{56}$ Pero la complejidad de las lecturas de Nelson y Luzuriaga no tuvieron un impacto considerable en la corriente principal de la recepción argentina de la obra de Dewey. Ésta permaneció aislada de las formulaciones filosóficas y políticas y aún psicológicas y epistemológicas y evitaba los matices y las dificultades de esta compleja obra.

Este patrón de lecturas didactizantes y pedagogizantes - en todo caso, despolitizadas - de la obra de Dewey no se limitó al trabajo de este educador, sino que afectó a los modos de recepción de la totalidad de la escuela nueva. Desde la década de 1920, los educadores argentinos escolanovistas habían desvinculado los objetivos de la reforma pedagógica de los objetivos más abarcadores de reforma y cambio social, definiendo así un campo de saber experto, el de los métodos y procedimientos, que muchos de estos maestros e inspectores consideraban que era básicamente apolítico. Por ejemplo, una revisión de los autores considerados como integrantes de la escuela nueva basado en las menciones de artículos de La Obra entre 1921 y 1945 muestra una negación absoluta de las experiencias soviéticas de las décadas de 1920 y 1930. También la predominancia de autores como Décroly, Ferrière, Cousinet y Montessori, que enfatizaban primordialmente los aspectos psicológicos de la acción educativa, es una muestra de esta tendencia. En la década de 1930, las tendencias nacionalistas en la sociedad y la política argentinas dominaron las decisiones curriculares y numerosos rituales "patrióticos" fueron introducidos en las escuelas en estos años. La cuestión de la naturaleza (in)compatible de las técnicas "norteamericanas" y el currículo "nacional" se convirtió en un topos de alta visibilidad.

En su trabajo, “¿Por qué tener escuelas progresivas?,” publicado en La Obra en el año 1933, Dewey se refirió justamente a esta cuestión. Reconocía que los métodos educativos variaban según los contextos sociales y políticos. Las escuelas "progresivas" — continuaba — son el producto de las sociedades modernas y éstas están organizadas de maneras muy diferentes. Pero en todas las sociedades - agregaba — incluso en los más diversos regímenes políticos, es posible conocer objetivamente las necesidades pedagógicas específicas de la población, de allí que ese espacio "técnico" de intervención reclamado por los maestros parecía estar legitimado en este artículo del norteamericano. ${ }^{57}$

Los maestros argentinos, atraídos por los nuevos lineamientos curriculares del gobierno conservador publicados en 1936, valoraron la posibilidad de una pedagogía 
escolanovista "neutral" en el terreno político. Este movimiento permitió a algunos docentes - al menos a aquellos que publicaban en las revistas - a consolidar su campo de saber experto y, simultáneamente, dotar este campo de un espíritu "progresivo," mientras continuaban apoyando y reproduciendo una cultura escolar basada en vínculos autoritarios. "Que la escuela activa no responde a ningún principio o régimen político, social o confesional," - afirmaban los editores de La Obra en 1944 - "lo prueba con harta elocuencia la circunstancia ya señalada de que sus diferentes formas aparecieron y se extendieron en países de los más dispares sistemas de gobierno." ${ }^{58}$ Este tipo de declaraciones intentaba demostrar de manera definitiva que la "orientación nacionalista de la enseñanza," afirmada por primera vez en 1931, ${ }^{59}$ no era necesariamente incompatible con el movimiento escolanovista en Argentina. La Educación Nueva "no sólo es perfectamente compatible con la orientación nacionalista que compete sostener a la enseñanza, sino que, como queda demostrado, no entraña el más insignificante obstáculo para el cumplimiento de la totalidad de los fines que el Estado ha establecido a sus escuelas." ${ }^{60}$ En este alegato, el autor mencionaba a Dewey para afirmar que la "escuela activa" sólo es "una forma de trabajo pedagógico." ${ }^{61}$ Mientras que en la década de 1930 La Obra publicó algunos artículos que habían analizado las viejas pedagogías como técnicas destinadas a la formación de "súbditos y esclavos," ${ }^{2}$ estas posiciones fueron declinando en los años siguientes, y los educadores "progresistas" buscaron rápidamente un compromiso con las fuerzas políticas determinantes de aquél tiempo marcadas por discursos autoritarios y por una renovación de la religiosidad.

En la década de 1940, la obra de Dewey pareció experimentar una nueva coyuntura de popularidad. Luego de la publicación de "Experiencia y educación" promovida por Luzuriaga en 1939, el educador español emprendió un proyecto ambicioso de traducciones y publicación de las obras educativas más importantes de Dewey. Continuó con la traducción y publicación en 1941 de "La ciencia de la educación" (original de 1929), con una segunda edición en 1944; publicó también en conjunto "El niño y el programa escolar. Mi credo pedagógico" (originales de 1925 y 1897 respectivamente) en Buenos Aires en el año 1944, libro que tuvo seis ediciones hasta 1967. "Democracia y educación" (original de 1916) apareció también publicado en Buenos Aires poco después del triunfo de Perón en las elecciones de 1946 y fue reeditado seis veces hasta 1971. Esta popularidad renovada de la obra de Dewey debe haber inspirado la invectiva ácre contra Dewey que Jordán Bruno Genta gritó a su público en ese año. Sólo en el contexto de esta ola de publicaciones patrocinadas por Luzuriaga, y en el marco del caldeado ambiente político del momento, puede entenderse la ansiedad por demás exagerada de Genta frente a la pretendida influencia de las ideas deweyanas en la educación argentina.

La revaluación de la obra de Dewey en los primeros años de la década de 1940, particularmente durante la dictadura militar nacional-católica entre 1943 y 1946, no fue solo un producto de las actividades de Luzuriaga ya que los textos mismos deberían haber estado a disposición de los maestros para ser revaluados. Fue también el resultado de un movimiento democrático creciente al interior del magisterio que se veía amenazado por las nuevas políticas autoritarias y pro-católicas del peronismo 
en ciernes. Estos maestros, en la tradición del exitoso normalismo tradicional argentino, encontraron en las ideas de Dewey la oportunidad de reestablecer un sentido de democracia y de republicanismo que parecía seriamente amenazado por Perón y su Partido Laborista. Sin embargo, esta revaloración se dio en profunda desconexión con la complejidad de las formulaciones de Dewey sobre democracia, autoridad y conocimiento. ${ }^{63}$ Los maestros argentinos identificaban la "democracia" en primer lugar con las regulaciones constitucionales de 1853. Ellos consideraban que en la vieja constitución "la democracia alcanza ... caracteres de mística, de una mística hondamente sentida y cálidamente abrazada ..." ${ }^{64}$ La mistificación de la constitución culminaba en la afirmación de su "carácter eterno" siendo ella la "más liberal del mundo." ${ }^{5}$ Para estos maestros, el grado relativamente alto de inclusión de las clases pobres en el sistema educativo argentino definía por sí mismo la naturaleza democrática de la escuela argentina. ${ }^{66}$ Otros aspectos del concepto de democracia de Dewey, por ejemplo su relación con el pluralismo y la diversidad, la crítica contra la cultura escolar autoritaria y su trabajo contrario a todo tipo de tendencias totalitarias en la sociedad, no constituyeron los focos de lectura de estos lectores de Dewey.

Una vez definido un campo dominado por un saber técnico y experto que implicaba una profunda despolitización de la pedagogía, los maestros argentinos que se identificaban como parte del movimiento escolanovista tuvieron que redefinir su vinculación con la política del momento. Esta reconsideración no sólo implicó una repolitización. Por el contrario, este grupo de maestros reafirmaba el carácter técnico de la pedagogía, la cual podría servir a diferentes proyectos políticos. Muchos maestros apoyaron en estos años dramáticos la coalición de izquierda-derecha compueta por conservadores, liberales, radicales, socialistas y comunistas contra Perón y mistificaron el republicanismo de viejo cuño y la constitución argentina de 1853 de tal manera que bloquearon cualquier discusión acerca de la democracia en las escuelas que fuera más allá de la integración de todos los niños en el aparato escolar. Los maestros liberales que hablaban de democracia después de 1946 lo hacían en fuerte oposición al gobierno electo de Perón y, al mismo tiempo, mistificaban el carácter "democrático" de las escuelas argentinas pre-peronistas. ${ }^{67}$ Por su parte, los maestros peronistas, incluso aquéllos que no se sentían identificados con la visión extrema de Genta no incluyeron a Dewey, un educador "extranjero," en sus luchas por redefinir "democracia” en torno a los derechos sociales y al bienestar de los trabajadores, perdiendo de vista el marco autoritario de la política peronista. De esta manera, por falta de voluntad o por las dificultades políticas y epistemológicas de percibir la obra de Dewey de manera diferente, la mayoría de los lectores argentinos del pragmatista norteamericano eran reacios a considerar los numerosos y polifacéticos aspectos del concepto de democracia vinculado al de educación que fueron planteados por Dewey.

\section{Comentarios finales}

Las lecturas de Dewey en el contexto argentino fueron tributarias tanto de las tradiciones, de las intenciones como de las situaciones de sus lectores. Estas tres dimensiones 
configuraron los patrones de significado que redujeron la complejidad de la obra de Dewey a cuestiones casi técnicas, cuando no era considerado como incompatible con la realidad nacional.

En primer lugar, las tradiciones liberales y republicanas en Argentina-esto es evidente en el reposicionamiento de los maestros en las disputas del año 1946 — redujeron sus complejas elaboraciones acerca de la democracia y redefinieron este concepto central como la continuación y extensión consecuente del patrón de inclusión social de la república conservadora que el naciente peronismo estaba cuestionando. En esta tradición, "democracia” fue reducida muchas veces a cuestiones republicanas de procedimiento institucional y no consideraba los aspectos de una democracia sustantiva fundada en el pluralismo y en la diversidad de identidades. Cuestiones como la deliberación apasionada, el progreso cultural y la cohesión social no eran parte de las discusiones sobre la escuela en la corriente principal de escolanovismo argentino. En segundo lugar, la intención de los maestros de lograr una posición como expertos respetables de un campo específico de prácticas sociales, como la pedagogía y la didáctica, también contribuyó a la producción de estas reducciones y, consecuentemente, Dewey fue "despolitizado." Su obra fue leída en gran parte como desvinculada de las controversias sociales y políticas del momento. Por último, las cambiantes situaciones políticas también favorecieron coyunturas distintas de la recepción. Frente a la "tendencia nacional en educación" imperante en las políticas educativas oficiales de la década de 1930, muchos maestros del campo escolanovista afirmaron la posible articulación del programa de reformas pedagógicas escolanovistas - incluyendo a Dewey mismo - con los diversos regímenes e ideologías de gobierno; de esta manera, reducían la figura del pedagogo norteamericano a la de mero proveedor de técnicas consideradas como políticamente "neutrales." Con la emergencia de Perón como líder político y del peronismo como nueva identidad política que impugnaba el patrón republicano hasta entonces imperante, "democracia” volvió a convertirse en un tema central, pero el concepto prevalente de democracia en la prensa educativa de aquellos años parece haber ignorado completamente las elaboraciones deweyianas sobre "democracia."

En este sentido, los recursos semánticos de los maestros argentinos, su posibilidad de atribuir nuevos significados al saber educativo "importado," estuvieron dados primordialmente a nivel de la selección más que de la interpretación. En otras palabras, el mecanismo central de "argentinizar" a Dewey no fue primeramente una interpretación divergente de sus posiciones, sino meramente una selección fuerte de sus escritos que estaba en consonancia con las tradiciones educativas oficiales, con las intenciones de legitimación y poder de los maestros y con las situaciones de enfrentamiento político del momento. Los educadores argentinos no "argentinizaron" a Dewey agregando a su obra nuevos significados. Más allá de los esfuerzos de publicación del español Luzuriaga, Dewey nunca afectaría el centro de las discusiones pedagógicas argentinas, aunque Jordán Bruno Genta creyera lo contrario. 


\section{Notas}

1. Entre la cuantiosa bibliografía sobre el ascendente internacional de la obra de Dewey, consultar: Thomas S. Popkewitz (comp.), Inventing the Modern Self and John Dewey: Modernities and the Traveling of Pragmatism in Education (Nueva York: Palgrave MacMillan, 2005); Gert Biesta, G. y Siebren Miedema, "Dewey in Europe: A Case Study on the international Dimensions of the Turn-of-the-Century Educational Reform," American Journal of Education 105 (1996): 1-26; Jaime Caicedo Escudero, "La escuela nueva y activa en América Latina. Influencia de Dewey en las reformas educacionales de Chile 1927 y 1945 ” en: VV.AA. Sociedad y educación. Ensayos sobre historia de la educación en América Latina (Bogotá: Universidad Pedagógica Nacional, 1995): 253-76; Marc Depaepe y Frank Simon, "La diseminación de ideas deweyanas en Bélgica a través de los manuales de pedagogía" en: Historia Caribe 10 (2005): 7-24; Jaime Nubiola and Beatriz Sierra, "La recepción de Dewey en España y Latinoamérica," Utopia y praxis latinoamericana 6 (2001).

2. Citado en "Dewey Stands Firm" en: Time, 21 de agosto de 1944.

3. Véase su carta de lectores en el número de Time del 11 de setiembre de 1944.

4. Éste era el término utilizado por los agents aunque refirió solamente a los Estados Unidos.

5. Sobre esta particular coyuntura política, incluyendo sus dimensiones educativas, puede consultarse Marcelo Caruso, "El año que vivimos en peligro. Izquierda, política y pedagogía” en: Adriana Puiggrós (dir.), Discursos pedagógicos e imaginario social en el peronismo (1945-1955) (Buenos Aires: Galerna, 1995), 43-106.

6. Juan Carlos Tedesco, Educación y sociedad en la Argentina (1880-1945) (Buenos Aires: Solar, 1986); véase también la discusión acerca de los modelos internacionales de progreso en la reforma de las escuelas primarias argentinas durante la república conservadora: Marcelo Caruso, "Zweideutige Verweise. Preußen als Vorbild argentinischer Schulreformen unter besonderer Berücksichtigung des Projekts von Carlos Saavedra Lamas" en Preußen und Lateinamerika, Sandra Carreras y Günther Mainhold eds. (Münster: Litt, 2004), 285-304.

7. Adriana Puiggrós, Sujetos, disciplina y currículum en los orígenes del sistema educativo argentino (Buenos Aires: Galerna, 1990); Carlos Escudé, El fracaso del proyecto argentino. Educación e ideología (Buenos Aires: Tesis, 1990); Roberto Alfredo Miranda y Osvaldo Miguel Iazzetta, Proyectos políticos y escuela, 1890-1920 (Rosario: Matética, 1982).

8. Tulio Halperin Donghi, El espejo de la historia. Problemas argentinos y perspectivas latinoamericanas, (Buenos Aires: Sudamericana, 1987), 160 y ss.

9. Jennie Howard, En otros años y climas distantes (Buenos Aires: Raigal, 1951).

10. Véase Carlos Escudé, 1942-1949. Gran Bretaña, Estados Unidos y la declinación argentina (Buenos Aires: Ed. de Belgrano, 1988).

11. Véase Charles Hale, "Political and social ideas in Latin America, 1870-1930," en The Cambridge History of Latin America, comp. por Leslie Bethell, Tomo 5 (Cambridge/UK: Cambridge University Press): 414 y ss.

12. Jaime Nubiola y Beatriz Sierra, "La recepción de Dewey en España y Latinoamérica" en: Utopia y Praxis Latinoamericana 6:13 (2001), 117. Una afirmación similar, aunque solo refiriéndose a Argentina y Brasil como los países pioneros de la recepción de la obra de Dewey, fue lanzada por William Brickman, "John Dewey's foreign reputation as an educator" en: School and Society 70 (22 de octubre de 1949): 261.

13. Sara Jafella, "Universidad Nacional de La Plata: dos concepciones en su período fundacional" en: Anales de la Educación comun 1 (2006): 196. 
14. Ernesto Nelson, "Introducción a la edición española” en: John Dewey, Psicologia del pensamiento (Boston: D. C. Health and Co., 1917): xii.

15. Ibid., xv-xvi.

16. Ibid., xix.

17. Ibid., xxi.

18. Véase i.e., Ernesto Nelson, The Spanish Reader (Boston: DC Heath and Co., 1916); Ernesto Nelson, Las bibliotecas en los EE.UU. (Washington: Dotación Carnegie para la Paz Internacional, 1929); Ernesto Nelson, La salud del niño, su protección social en la legislación y en las obras (New York: La nueva democracia, 1929).

19. Víctor Mercante, Charlas pedagógicas (Buenos Aires: R. Gleizer, 1927), 12.

20. Raúl B. Díaz, Ideales y esperanzas en educación común (Buenos Aires: Talleres Gráficos de L. J. Roso y Cía., 1913), 1. En su perspectiva, los Estados Unidos eran el único páis del mundo que podría mostrar una escuela que era el "el centro de la vida y la felicidad del niño, cercana a su casa ... guiada por los ideales nacionales de democracia y grandeza."

21. Para una visión general de este período: Argentina en la paz de dos guerras, 1914-1945, comp. Waldo Ansaldi, Alfredo Pucciarelli y José C. Villarruel (Buenos Aires: Biblos, 1993).

22. María Delia Terrén de Ferro, Historia de la instrucción pública en la Argentina, 1916-1930. Formas institucionalizadas de enseñanza (Buenos Aires: Ediciones Universidad del Salvador, 1996).

23. Véase una primera contribución en: Inés Dussel y Marcelo Caruso, "Specters of Dewey in Latin America: Some Notes on the Reception of Educational Theories" en Paedagogica Historica Supplementary Series. Tomo III (1998), 380-86. Asimismo, Marcelo Caruso, "John Dewey und Jean Piaget: Weltklassiker im lateinamerikanischen Kontext" en: Jürgen Schriewer (comp.), Weltkultur und kulturelle Bedeutungswelten. Zur Globalisierung von Bildungsdiskursen (Fráncfort/M. y Nueva York: Campus, 2007): 75-116.

24. Juan Bautista Terán, Espiritualizar nuestra escuela. La instrucción primaria argentina en 1931 (Buenos Aires: Librería del Colegio, 1932).

25. Ibid., 4.

26. Ibid., 12.

27. Ibid., 13.

28. Ibid., 42.

29. Aníbal Ponce, Educación y lucha de clases (Buenos Aires: Cartago, 1984), 163. También criticó la segunda tendencia esclonavista, la de los "doctrinarios."

30. Véase el estudio de Oscar Terán, "Aníbal Ponce o el marxismo sin nación” en: Oscar Terán, En busca de la ideología argentina (Buenos Aires: Catálogos, 1986): 131-78.

31. Consultar Herbert Kliebard, The Struggle for the American Curriculum, 1896-1958 (Nueva York: Routledge, 1986), quien argumenta en contra de este reduccionismo.

32. Nos referimos aquí a la obra de Basil Bernstein sobre la estructuración de los discursos pedagógicos. La gramática pedagógica official se refiere al conjunto hegemónico de "reglas que regulan la producción, distribución, reproducción, interrelación y cambio de los textos pedagógicos legítimos (textos), sus relaciones sociales de adquisición y transmisión (práctica) y la organización de sus contextos (organización)." Basil Bernstein, The Structuring of Pedagogic Discourse. Class, Codes and Control vol. IV (Londres y Nueva York: Routledge, 1990), 193. 
33. Un educador anarquista, José María Lunazzi, escribió una crítica adicional, muy similar a la de Aníbal Ponce. En su libro Reconstrucción educacional (Buenos Aires: Claridad, 1935) acusa a Dewey de no querer tranformar las condiciones sociales que producen la desigualdad y la injusticia y de solo trabajar para que la escuela se ajuste a su medio social. Llega casi a la injuria cuando dice que la pedagogía de Dewey puede ser considerada propia de un "mercachifle practicismo" (64). El único aspecto en el que Lunazzi se diferencia de la posición de Ponce es su defensa de la educación material y técnica y exige un balance entre la educación intelectual y el contacto con la vida social. 132.

34. Jesualdo, Los fundamentos de la nueva pedagogía (Buenos Aires: Ed. Americalee, 1943),

35. Jesualdo, Diecisiete educadores de América. Los constructores, los reformadores (Montevideo: Ed. Pueblos Unidos, 1945), 198.

36. Ibid., 199.

37. A diferencia del caso chileno, donde el jesuita Alberto Hurtado discutió en profundidad la pedagogía deweyiana, no existe en Argentina un estudio similiar.

38. Adriana Puiggrós, "La educación argentina desde la reforma Saavedra-Lamas hasta el fin de la década infame" en: Escuela, democracia y orden (1916-1943), comp. Adriana Puiggrós (Buenos Aires: Galerna, 1992): 95.

39. Consultar Puiggrós, "La educación argentina" 95 y Silvina Gvirtz, El discurso escolar a través de los cuadernos de clase (1930-1970) (Buenos Aires: Eudeba, 1999).

40. Queremos agradecer aquí a Gabriela Trentin (Universidad Humboldt, Berlín) y Leandro Stagno (Universidad de La Plata, Argentina) por su asistencia en la búsqueda y reproducción del material vinculado con estas dos publicaciones. 324.

41. J. M., "El niño y el programa escolar, de John Dewey" en: La Obra V:95 (1925):

42. Estelle Louise Jovin, "La educación progresiva en Estados Unidos" en: La Obra XIV:254 (1934): 707.

43. John Dewey, "Algunos aspectos de la educación moderna" en: El Monitor de la Educación Común LI:705 (1931): 187.

44. Juan Carlos Agulla, "La escuela nueva" en: El Monitor de la Educación Común LX:815 (1940): 20-25.

45. Luis Galdames, "Algunos aspectos de la educación primaria en Norte América” en: El Monitor de la Educación Común LI:712 (1932): 39. 201.

406. Pedro W. Bustos, "Renovar la escuela desde la escuela" en: La Obra XI:196 (1931):

47. John Dewey, "De la oposición entre el programa escolar y el niño" en: La Obra V:94 (1925): 297; John Dewey, "Mi credo pedagógico" en: La Obra XI:196 (1931): 198-99 y XI:197 (1931): 250-52; John Dewey, “¿Por qué tener escuelas progresivas?” en: La Obra XIII:233 (1933): 435-437 y XIII:234 (1933): 483-485.

48. John Dewey, "Algunos aspectos de la educación moderna," 42.

49. Hugo Biagini, Filosofía américana e identidad. El conflictivo caso argentino (Buenos Aires: EUDEBA, 1989).

50. J. M. "El niño y el programa escolar, de John Dewey," 324.

51. Emilio Abelleyra, "Fundamentos de la escuela renovada" en: El Monitor de la Educación Común LI:707/708 (1932): 117. 
52. Rosario Vera Peñaloza, "Los jardines de infantes y las escuelas nuevas" en: El Monitor de la Educación Común LI:713 (1932): 86.

53. Luis Borruat, "Orientaciones y organización de la escuela moderna" en: La Obra, II:38 (1922), 4-6; también "La escuela activa” en: La Obra IV:77 (1924): 433-34.

54. Al mismo tiempo, otros educadores latinoamericanos presentaron un Dewey "puramente" psicológico. Estos trabajos serían muy populares entre los docentes. Véase Lourenço Filho, "Principios fundamentales de la educación activa o funcional" en: La Obra XIII:229 (1933): 243-46.

55. Lorenzo Luzuriaga, "La pedagogía de Dewey" en: La Obra II:42 (1922): 12. Véase también, en la misma línea, Lorenzo Luzuriaga, "La escuela activa" en: La Obra V:105 (1925): 828-29.

56. Ernesto Nelson, "La educación en las obras de previsión y de protección a la infancia" en: El Monitor de la educación común LI:710 (1932): 73-88; Ernesto Nelson, "Significado, finalidades y formas de la acción social popular" en: El Monitor de la Educación Común LI:712 (1932): 9-19.

57. John Dewey, “¿Por qué tener escuelas progresivas?” en: La Obra XIII:233 (1933): 436. El segundo artículo fue publicado en La Obra, XIII:234 (1933): 483-85.

58. "Que la escuela activa no responde a ningún principio o régimen político, social o confesional, lo prueba con harta elocuencia la circunstancia ya señalada de que sus diferentes formas aparecieron y se extendieron en países de los más dispares sistemas de gobierno." Ver: "La escuela en acción. La escuela activa" en: La Obra XXIV:411 (1944): 469.

59. Véase "El Consejo Nacional de Educación rearfirma la orientación nacionalista de la enseñanza” en: El Monitor de la Educación Común L:704 (1931): 119-20.

60. "La escuela en acción. La escuela activa," 470.

61. Ibid. 294.

62. Elisabeth Huguenin, "La práctica de la escuela activa” en: La Obra XIII:230 (1933):

63. Véanse, entre otros estudios destacados, las siguientes investigaciones: Robert Westbrook, John Dewey and American Democracy (Ithaca: Cornell University Press, 1991); Alan Ryan, John Dewey and the High Tide of American Liberalism (Nueva York y Londres: W.W. Norton \& Co, 1995).

64. "Pueblo demócrata" en: La Obra XXV:418 (1945): 90.

65. "Principios liberales" en: La Obra XXV:419 (1945): 138.

66. "La escuela, puntal de la democracia" en: La Obra XXIV:410 (1944): 423.

67. Sobre este discurso en las izquierdas políticas argentinas, consultar, Caruso, "El año que vivimos en peligro." 
